\title{
Estudos sobre orçamento e gestão nos países da OCDE - uma proposta de estrutura*
}

\author{
Serviço de Gestão Pública/Comitê de \\ Gestão Pública - PUMA/OCDE
}

\section{Introdução}

\section{Antecedentes}

O Comitê de Gestão Pública da OCDE (Public Management Service - PUMA) elegeu, como um dos principais produtos de suas atividades, a elaboração de análises de sistemas nacionais de orçamento e gestão. O presente documento detalha a estrutura proposta para a realização dessas análises.

O Comitê entende que a credibilidade de tais estudos dependerá da aceitabilidade desta estrutura de análise. Para desenvolvê-la e definir os processos para a realização dos estudos de cada país, a secretaria da Organização para a Cooperação e o Desenvolvimento Econômico (OCDE) coletou, inter alia, informações das seguintes fontes:

a) análise do sistema orçamentário da Suécia, apresentado na reunião dos diretores de orçamento, em maio de 1998;

b) estudo solicitado pela secretaria, revisando questões relativas à integração da gestão financeira com a gestão de desempenho, com atenção particular à avaliação da natureza das barreiras para tal integração, completado em setembro de 1998;

c) análise das estruturas e processos utilizados em outros estudos desta natureza, incluindo:

- análises dos casos de diversos países realizadas anualmente pelo Comitê da OCDE para Revisão da Economia e Desenvolvimento (Economic and Development Review Committee - EDRC);

Organização

para a

Cooperação e o

Desenvolvimento

Econômico

(OCDE), Paris,

França.

Contato:

www.oecd.org
Traduzido por Maria Christiana Ervilha 
- análises comparativas realizadas pelo Comitê da OCDE para Assistência ao Desenvolvimento (Development Assistance Committee - DAC);

- estudos sobre o marco regulatório da OCDE;

- estudos financiados pelos próprios países — por exemplo, o estudo de Pollitt sobre a Finlândia; o estudo de Schick sobre a Nova Zelândia;

- agências de classificação de risco financeiro e de competitividade, tais como Standard \& Poor, Moodys, IMD; e

d) padrões e melhores práticas para sistemas de gestão - gestão financeira, de desempenho e de recursos humanos — publicados por organizações tais como: o Banco Mundial, Fundo Monetário Internacional (FMI), International Federation of Accountants (IFAC) e, certamente, OCDE e PUMA.

\section{Estrutura-padrão para critérios de análise}

Durante sua reunião de outubro de 1998, o Comitê PUMA decidiu que as análises revisariam seis questões principais para os estudos de cada país.

- Estratégias: uma vez que as prioridades e orientações tenham sido estabelecidas, como elas são articuladas pelo governo?

- Cordenação: como são articuladas e implementadas as intervenções governamentais para garantir que elas apóiem as estratégias?

- Gestão e controle: como são distribuídos os poderes decisórios em termos de recursos financeiros, humanos e organizacionais?

- Accountability e transparência: quão claras e diretas são as linhas de responsabilidade acerca da estratégia, coordenação e execução das decisões e qual é a qualidade da informação disponível para monitorar e avaliar a accountability?

- O papel do Poder Legislativo: qual é o papel do Poder Legislativo na estratégia, coordenação, gestão, controle e accountability? Ele é claramente delineado a partir do papel do executivo?

- Transformação gerencial: quais sistemas criam processos dinâmicos para "o desafio e a mudança", incluindo a capacidade de prever e enfrentar choques ou alguma necessidade inesperada de mudança de estratégia, estrutura ou capacidade, para a implementação das prioridades governamentais? Como se coleta informação para alimentar essa atividade estratégica de análise?

O presente documento apresenta um resumo do desenvolvimento dessa estrutura de análise. Seus elementos específicos são discutidos na seção "Principais aspectos do sistema de orçamento e gestão". As próximas 
duas seções apresentam princípios importantes para o desenvolvimento dessa estrutura. A seção II estabelece os objetivos-chave da elaboração do orçamento e da gestão do setor público. Por sua vez, a seção III analisa alguns problemas particulares inerentes à elaboração do orçamento e à gestão pública, além de tratar do desenho de sistemas de gestão financeira e de gestão de desempenho para resolver tais problemas. Isso permite que a discussão na seção "Principais aspectos do sistema de orçamento e de gestão" se dê a partir de um entendimento comum de tais princípios.

\section{Objetivos da elaboração orçamentária e da gestão}

A administração e o processo de elaboração do orçamento público tradicionalmente têm se baseado em sistemas de normas de procedimento. Entrentanto, inovações recentes dos sistemas de orçamento e gestão têm focalizado mais a obtenção de resultados e não a observância de tais normas de procedimento. Apesar de o alcance de tais resultados se basear na operação de processos, a prática moderna indica que a administração e a elaboração orçamentária não são processos em si mesmos, mas estão interligadas por um conjunto maior de arranjos institucionais e governamentais.

O desenho desses arranjos tem visado à consecução dos seguintes objetivos:

- implantar e manter a disciplina fiscal agregada (isto é, garantir que o governo não gaste, de modo geral, mais do que o necessário para atingir seus objetivos políticos coletivos);

- alocar recursos de acordo com as prioridades governamentais (ou seja, gastar naquilo que é considerado politicamente mais importante — eficiência alocativa); e

- promover eficiência no uso dos recursos orçamentários para executar programas e serviços (ou seja, encorajar a eficiência técnica).

O uso desses três objetivos para a definição do desenho dos sistemas de gestão pública — do gasto público — está se tornando cada vez mais aceito. Em trabalho realizado para os Técnicos em Orçamento do Partido Trabalhista (Senior Budget Officials Working Party), Allen Schick relacionou esses três objetivos ao papel do órgão central de orçamento. Esta estrutura de análise também foi adotada pelo Banco Mundial, Banco de Desenvolvimento Asiático, FMI e outros. Embora haja debate acerca da inter-relação entre fins e meios, decidimos adotar esses três objetivos como os objetivos centrais a serem perseguidos pelo sistema de elaboração de orçamento de gestão. 
Da mesma forma, a principal função das análises será documentar os principais caminhos que os países buscaram para atingir tais objetivos e identificar as fontes de distorção ou impedimentos para sua consecução. Ela envolverá a verificação de quais sistemas, instituições e processos nacionais estão operando para favorecer tais metas de eficiência.

Uma regra geral importante é que essa eficiência tenha, na maior extensão possível, um sentido dinâmico. Isso significa que as estratégias ou instrumentos que optem por não seguir os arranjos correntes ou determinem dinâmicas instáveis têm menos possibilidade de ser consistentes com a consecução desses objetivos no decorrer do tempo. Essa é uma área difícil, em que as análises tendem a ser mais subjetivas e as estratégias podem refletir o ambiente das instituições locais. Há, entretanto, recentes experiências em alguns países que passaram por reformas da gestão pública e de governança, que destacam a aplicabilidade de algumas estratégias de reforma e a não-aplicabilidade de outras. ${ }^{1}$

\section{Principais problemas da elaboração orçamentária e da gestão}

Recentemente foram realizados inúmeros estudos a respeito das instituições de orçamento e de sua influência na consecução dos três objetivos de eficiência.

Campos e Pradhan, ${ }^{2}$ em trabalho realizado sobre instituições orçamentárias, descrevem três problemas-chave inter-relacionados, todos ligados ao alcance de tais objetivos. O primeiro é a "tragédia dos comuns", em que o orçamento é visto como um poço comum de recursos, no qual vários atores, i.e., interesses setoriais, disputam esses recursos sem qualquer custo. Em segundo lugar, os problemas na disseminação de informação e do "ciclo de votação", que podem impedir a dotação estratégica de alocações para as prioridades governamentais. E, finalmente, a assimetria informacional e os incentivos inadequados ou incompatíveis dentro do governo - problemas do tipo principal-agente - , que podem impedir a alocação e o uso eficientes dos recursos. Nas palavras de Schick, se os níveis de recursos pudessem simplesmente ser elevados, para cobrir as crescentes demandas por gasto, não existiriam problemas de alocação de recursos. ${ }^{3}$

Em dois trabalhos recentes, Schick documenta o estado da arte nos caminhos de confrontação desse e de outros problemas de alocação de recursos no sistema orçamentário. Por exemplo, ele cita uma série de práticas consistentes com a existência de um sistema orçamentário voltado para a realocação.

As análises do PUMA buscarão evidências de que os problemas identificados acima estão sendo administrados de forma adequada. Isso 
significa examinar a alocação de incentivos, a informação e funções. Isso

é consistente com a literatura recente, que observa o comportamento da gestão pública por meio da análise das instituições. ${ }^{4}$

\section{Integração da gestão de desempenho com a gestão financeira}

As abordagens analíticas que adotaram os três objetivos de eficiência tendem a ser associadas ou à gestão do gasto, ou à gestão orçamentária, e não aos aspectos mais amplos da gestão pública. Uma exceção é Pollitt, que também usou esses objetivos em seu estudo sobre a integração da gestão de desempenho e financeira. ${ }^{5}$

Seu argumento é de que, em um cenário ideal, os sistemas de gestão financeira e de desempenho, incluindo a gestão dos recursos humanos, estão associados a instrumentos, sistemas de incentivos e arranjos institucionais, por meio dos quais os governos buscam mitigar ou minimizar os problemas de alocação de recursos e maximizar o alcance dos objetivos.

Ao fazê-lo, tanto os sistemas de gestão financeira quanto os de gestão de desempenho compartilham quatro objetivos-chave subsidiários, embora os processos e aptidões envolvidos para atingi-los sejam possivelmente distintos:

- estabelecer objetivos e alocações para as ações governamentais ou seja, baseados em insumos, produtos e/ou resultados; incrementalismo histórico ou definição de prioridades estratégicas;

- estabelecer os tipos de autoridades para realizar tais ações isto é, centralizada, descentralizada, delegada ${ }^{6}$, contratual e legal;

- determinar qual informação é necessária para saber se as ações estão sendo executadas de maneira apropriada, ou seja, mensuração, informação e registro das necessidades; e

- criar recompensas e sanções para o desempenho, isto é, estruturas de accountability e sistemas de incentivos.

Em um sistema de gestão de recursos que funciona bem, os processos de gestão financeira e de gestão do desempenho utilizarão processos que se complementam e se apóiam mutuamente. Os quatro aspectos compartilhados do desenho de sistemas, por exemplo, têm muito em comum com o que Schick chama de "regras, papéis e informação".

Apesar dos interesses comuns entre o desempenho e a gestão financeira, as evidências sugerem que uma fonte comum de perturbação no alcance das metas compartilhadas de eficiência é a baixa integração entre os dois sistemas. ${ }^{7} \mathrm{Na}$ verdade, essa integração requer uma coordenação da ação, mas nem sempre os interesses dos vários defensores da gestão financeira e de desempenho estarão tão bem alinhados. Em sistemas não integrados, um conjunto de comportamentos pode ser encorajado por um 
sistema e desencorajado por outro. Por exemplo, o downsizing em um departamento governamental pode ser encorajado pelo sistema orçamentário, mas influenciar negativamente a carreira do ministro ou dos funcionários mais graduados envolvidos no processo. Assim, nesse caso, a habilidade de o sistema como um todo de atingir os objetivos de eficiência será comprometida.

Como afirma Pollitt, os sistemas de gestão financeira e de gestão de desempenho tendem a desenvolver-se separadamente como sistemas paralelos, que podem ou não — ou apenas em determinado grau — ser harmoniosos ou mesmo compatíveis.

\section{Observando processos como fonte de integração e não-integração}

Existem, em geral, vários processos distintos que podem ser identificados com o sistema de gestão financeira, e outros que se identificam com o sistema de gestão de desempenho.

A gestão financeira, em termos gerais, envolve: ${ }^{8}$

O controle e a operação do ciclo "orçamento - contabilidade - auditoria", inserida em um ciclo maior de gestão e políticas públicas — reparação e planejamento, tomada de decisão, implementação, monitoramento e controle, avaliação e feedback.

A afirmação anterior condiz com a existência de sistemas de gestão financeira que incluem atividades como, por exemplo, gestão de fluxo de caixa, compras, cobrança da dívida, gestão da propriedade e do risco. Também vale a pena observar que, embora exista uma aspiração normativa geral de que a gestão financeira pertença sempre ao sistema mais amplo de planejamento, avaliação e feedback, isso não é, de forma alguma, a regra geral na prática. De fato, tais atividades são, muitas vezes, identificadas mais claramente com a gestão de "desempenho".

Porém, a definição da gestão de desempenho não é simples. Ela pode significar coisas distintas em sistemas administrativos diferentes da mais básica gestão do desempenho do funcionário em uma administração altamente centralizada ao veículo para estabelecer e gerenciar as prioridades estratégicas mais importantes do governo e transformá-las em produtos estratégicos que alcançam, em efeito cascata, as organizações e indivíduos.

A OCDE descreveu a gestão de desempenho conforme a última definição, ou seja, em seus aspectos estratégicos, no contexto das novas reformas da gestão pública. Para o propósito desta discussão, um sistema de gestão de desempenho é definido por uma série de processos, que consiste em ${ }^{9}$ : 
- definir objetivos e metas de desempenho para os programas;

- dar aos gerentes responsáveis pelos programas a liberdade para implementar processos, para que possam alcançar tais objetivos e metas;

- medir e relatar o nível real de desempenho em relação a tais objetivos e metas;

- fornecer informações a respeito do nível de desempenho, que alimentam as decisões sobre financiamentos futuros dos programas, mudanças nos seus conteúdos ou desenhos, e estabelecer prêmios ou penalidades individuais ou organizacionais; e

- fornecer informação ex post para órgãos revisores, tais como comitês legislativos e auditores externos - dependendo do mandato relativo ao desempenho que os últimos tenham —, cujas opiniões também podem alimentar as decisões mencionadas no item anterior.

A abordagem geral ligada à gestão de desempenho refere-se a retirar o foco da atenção dada aos insumos e aos controles ex ante, transferindo-a para o esclarecimento das expectativas e mensurações de resultados e a conseqüente ação ex post. Tal abordagem apóia-se na descentralização da autoridade gerencial, para atingir formas mais explícitas de accountability ligadas a produtos e resultados, tais como o alcance de metas por parte de indivíduos ou unidades. $\mathrm{O}$ controle torna-se mais estratégico e menos preocupado com a observância dos processos prescritos — "orientação" em vez de "controle".

Um sistema desenvolvido de gestão de desempenho envolve incentivos, recompensas e sanções para tradução dos objetivos de desempenho, da mensuração e da accountability para o nível da equipe.

Em resumo, ao compararmos a orientação dos sistemas de gestão financeira com aqueles de gestão de desempenho, algumas sobreposições e reforços mútuos ficam imediatamente aparentes. Sistemas de gestão financeira visam agregar a disciplina fiscal em nível macro e também uma maior eficiência na entrega dos serviços. Em consonância com os mesmos objetivos, a gestão de desempenho visa elevar a eficiência em níveis micro e intermediário.

A gestão financeira busca alocar recursos de forma a concentrá-los naqueles programas que são as maiores prioridades políticas. Em princípio, deveria haver uma ligação entre esse objetivo e o propósito da gestão de desempenho de elevar a qualidade e a eficácia dos programas, à medida que os líderes políticos passem a dar prioridade aos programas que funcionam bem e cumprem seus objetivos. Além disso, aumentar a accountability caracteriza-se como meta tanto da gestão financeira quanto da gestão de desempenho. De qualquer forma, a gestão financeira e a gestão de desempenho compartilham uma "mesma missão".

Pollitt identificou várias fontes de perturbação na integração dos sistemas de gestão financeira e de desempenho. Embora aspectos mais 
detalhados de seus argumentos estejam contidos no Anexo, de forma sucinta, eles são:

- a tentativa de fazer muito ao mesmo tempo: a tentativa simultânea de reformar o sistema de orçamento e introduzir a gestão de desempenho pode fracassar. Esse é um problema de gestão da mudança;

- o conforto da ambigüidade: um certo grau de ambigüidade pode ajudar os políticos a formar coalizões de interesses em defesa do controle e da realocação. Isso não condiz com as bases dos sistemas de gestão de desempenho, fundadas na clareza das expectativas e do desempenho;

- a defesa da área: servidores públicos e outros indivíduos podem ser levados a proteger seus programas ou área de atuação e tentar evitar comparações claras e bem fundamentadas;

- a divergência cultural: as perspectivas e ferramentas trazidas para a gestão financeira e para a gestão de desempenho podem ser bastante distintas. Em geral, os engenheiros da gestão financeira são "devoradores de números", ao passo que os engenheiros da gestão de desempenho tendem a ser mais preocupados com temas como qualidade, mudança cultural e desenvolvimento de capacidade; e

- a atribuição dos resultados: a gestão de desempenho pressupõe a mensuração de produtos e resultados. Contudo, a gestão financeira tem problemas em lidar, de forma adequada, com os resultados, em razão das múltiplas fontes de influência.

A opinião de Pollitt é que os esforços de integração deveriam se concentrar nas áreas onde tal integração não é tão difícil. De qualquer modo, a capacidade de lidar com os problemas listados acima deveria fornecer uma forte indicação da situação do sistema de orçamento e gestão de um determinado país.

\section{Principais aspectos do sistema de orçamento e gestão}

A estrutura-padrão de análise propõe a identificação dos pontos fortes e das fraquezas dos sistemas pré-existentes nos países analisados. Isso é feito por meio da verificação dos cinco aspectos principais de um sistema de orçamento e gestão: estratégia e coordenação; gestão e controle; accountability e transparência; o papel do Poder Legislativo; e a transformação gerencial.

As próximas seções descrevem a aplicação de cada um desses aspectos na análise do caso de determinado país. 


\section{Estratégia e coordenação}

Quadro 1: Documento da reunião do Comitê PUMA, realizada em outubro de 1998

Estratégias: uma vez que as prioridades e orientações políticas tenham sido estabelecidas, elas são articuladas pelo governo:

- no governo como um todo, de forma setorial e em nível organizacional;

- dentro dos setores governamentais internos e externos, ou seja, o governo central e empresas estatais, ministérios e agências); e

- entre os níveis governamentais.

Coordenação: como as intervenções governamentais são coordenadas e implementadas para garantir que funcionem de forma a apoiar a estratégia, incluindo a capacidade de:

- manter a disciplina fiscal agregada;

- alocar recursos de acordo com as prioridades governamentais - planejamento/ elaboração orçamentária; e

- integrar a gestão de insumos e produtos.

Se não houvesse escassez, não haveria problemas de alocação de recursos. O ganho pretendido com a ação coordenada é que os recursos escassos sejam alocados de modo eficiente. Isso requer que a informação flua, para permitir que as muitas solicitações daqueles que buscam recursos sejam consideradas.

Há uma grande diferença entre os setores governamental e privado no momento de enfrentar o problema de escassez de recursos, porque o governo tem o poder de extrair compulsoriamente recursos de outros pelo poder da taxação e da apropriação de propriedade. Por essas duas razões, o objetivo de eficiência mais elevado ${ }^{10}$ relacionado à reserva agregada de recursos é muito importante.

A falta de uma forte restrição orçamentária no suprimento agregado de recursos pode diminuir os incentivos para uma ação coordenada e permitir que o governo, ao contrário, busque o aumento de impostos para financiar os projetos prediletos de determinados ministérios e eleitores. Aqui se apresentam, ao menos, dois problemas: um é que os custos dos programas financiados por impostos são divididos por todos, ao passo que os benefícios costumam ser direcionados e "capturados" por um grupo menor; e o outro problema é que alguns políticos e outros indivíduos podem acreditar que sua reputação depende de sua capacidade de defender seu portfolio dos cortes de recursos, sendo assim mais provável que concordem com aumentos de recursos do que com cortes. ${ }^{11}$ Se cada parte envolvida no processo decisório acreditar que seus interesses estão ligados ao aumento de recursos, então ele tem grande probabilidade de ocorrer. 
A interação desses dois fatores sugere que a coordenação eficiente exige tanto um teto rígido para o orçamento para agregar o gasto, quanto a tradução desse teto em um portfolio subsidiário ou setorial. Os papéis do ministro da economia e do gabinete reforçam tais regras e fornecem um ponto importante de influência compensatória às preferências individuais dos ministros setoriais. O principal instrumento desenvolvido, nos anos recentes, para a adoção de tais tetos tem sido a estrutura de despesas de meio período. Tais estruturas têm uma grande variedade de formas e envolvem vários graus de compromisso por parte do Executivo, e, algumas vezes, do Legislativo.

Se os tetos agregados e setoriais forem impostos, o que restará a ser feito como ação coordenada? Tetos imutáveis indicam governos insensíveis às mudanças de circunstâncias, preferências, tecnologias e informação. Da mesma forma, dentro do nível mais alto de tetos agregados, é preciso que os recursos sejam transferidos para refletir tais mudanças.

A realocação é difícil porque gera disputas por recursos. Mas a realocação - especialmente em tempos de recursos fiscais limitados é uma forma de dar efeito às mudanças nas políticas públicas e nas prioridades. O principal instrumento para consegui-la é o desenvolvimento e a aplicação de estratégias, e o principal sistema decisório para implementar estratégias é o orçamento e os sistemas de gestão a ele relacionados.

No decorrer da história, muitos países atenderam à necessidade de serem estratégicos por meio de planejamentos plurianuais. Tendências mais recentes afirmam que o ponto de partida de tais planos era uma forma inviável de guiar o governo em um momento que requer mudanças rápidas. Já, no setor privado, a preparação, comunicação e reavaliação da estratégia tornaram-se uma atividade perene, e não mais intermitente. Como afirma Schick, "o alinhamento estratégico é um elemento central da noção de propriedade (ownership), visto que, se os objetivos e políticas de um departamento não forem congruentes com aqueles do governo, pode haver dano real à capacidade de ação coletiva". ${ }^{12}$

A concretização desse alinhamento estratégico pode exigir uma divisão de responsabilidades entre aqueles que tomam as decisões em nível central e os demais, localizados nos departamentos e agências. O centro precisa gerenciar sua agenda cuidadosamente, de modo que o escasso tempo dos ministros e dos burocratas de níveis mais elevados possa ser dedicado a temas mais relevantes — definição de prioridades estratégicas, e não gerência operacional. Assim, a consecução dos objetivos estratégicos requer um sistema de gestão e controle mutuamente compatível. 


\section{Gestão e controle}

Quadro 2: Documento da reunião do Comitê PUMA, realizada em outubro de 1998

Gestão e controle: como são distribuídos os poderes decisórios que dizem respeito aos recursos financeiros, humanos e organizacionais, para:

- promover a eficiência na distribuição dos recursos nos setores governamentais interno e externo;

- determinar o desempenho, os objetivos e as metas de intervenções específicas;

- definir o poder discricionário gerencial, para a consecução de objetivos e metas; e

- práticas, incentivos etc., de recursos humanos e informação, com suas prioridades.

Em um mundo ideal, onde tudo é previsível, onde coletar e transmitir informações não custa nada e onde primeiros-ministros e presidentes têm uma capacidade de processamento infinita e podem direcionar seus subordinados a fazerem exatamente o que eles necessitam, todas as decisões poderiam ser tomadas de modo ótimo em nível central. Mas tais condições não se aplicam ao mundo real.

Todo sistema de gestão exige a distribuição dos poderes de decisão entre os vários atores envolvidos. Recentemente, muitas das reformas de gestão pública dedicaram-se a modificar a posição desses poderes decisórios. Embora a tendência geral tenha sido a da devolução (devolution) e descentralização, há alguns casos em que a recentralização tem sido promovida. ${ }^{13} \mathrm{Na}$ linguagem aceita pela gestão pública, devolução geralmente envolve mudança de funções do nível mais alto para outros mais baixos dentro do governo, ao passo que a descentralização implica que um maior escopo da tomada de decisão sobre a utilização de recursos seja transferido para níveis inferiores dentro da mesma jurisdição administrativa.

Ambas as tendências encorajam a crescente especialização administrativa e gerencial, o que permite que o nível central concentre-se em desenhar as estratégias e as políticas principais e que os níveis mais baixos utilizem a informação local para informar as decisões referentes à alocação de recurso local.

A questão do grau ótimo de descentralização é complicada. A resposta depende de vários fatores, tais como os sistemas formais e informais para transmissão de informações, elaboração de estratégias e enfrentamento do risco. É suficiente dizer que o desenvolvimento de novas instituições administrativas e tecnologias tem, geralmente, apoiado a crescente descentralização. Existem ao menos cinco razões principais para a descentralização. ${ }^{14}$ 
Primeiro, é difícil — senão impossível — fazer chegar toda a informação local à gerência central. Assim, ao invés de tentar gerar sistemas que transfiram toda a informação ao nível central, os poderes decisórios podem ser descentralizados para onde as informações mais relevantes são coletadas, mantidas, acessadas e processadas. Segundo, decisões descentralizadas podem ser mais ágeis. A tomada de decisão centralizada precisa levar a informação relevante, para decisão, da área local para o centro, as deliberações para os centros de decisão, e transmiti-la de volta. Tudo isso requer tempo e reduz a capacidade de resposta. Terceiro, se muitas decisões operacionais acumulam-se em nível central, elas congestionam o tempo de deliberação disponível, em nível central, tomada de decisão, tumultuando sua capacidade de refletir e decidir sobre temas mais importantes em termos estratégicos. Quarto, há uma enorme complexidade de processamento para um número relativamente pequeno de atores, em nível central, com autoridade para tomar as decisões mais acertadas. Por último, o direito de tomar decisões pode ser uma força motivadora e inovadora. A idéia do empowerment é relativamente nova na gestão pública. O nível em que ele ocorre está ligado, ao menos de certa forma, à propensão do ambiente em dividir o risco.

Assumindo uma posição mais conciliadora, Stiglitz afirma que um processo decisório mais descentralizado - realizado corretamente - corre o risco de estar associado a uma menor variação na qualidade da decisão, em que menos projetos bons são rejeitados e em que há crescentes oportunidades para experimentação e aprendizagem. ${ }^{15}$

Entretanto, aceitar as razões para descentralizar é uma coisa; desenhar um sistema de tomada de decisão e monitoramento descentralizados, em apoio a essa descentralização, é outra. Quando isso é feito, há normalmente três problemas principais a serem gerenciados:

- primeiro, há o problema da congruência de metas - o fato de que as metas do agente não serão idênticas às metas do principal;

- segundo, há problemas criados pelas externalidades — o fato de que as consequiências oriundas da ação ou decisão podem afetar outros atores, além dos envolvidos no processo decisório; e

- terceiro, há problemas associados com o compartilhamento do risco - as preferências do risco e as escolhas de retorno de risco disponíveis podem ser diferentes para cada participante de um dado sistema.

Torna-se parte da tarefa de coordenação, controle e gerência de um sistema enfrentar os problemas ligados ao alcance das metas de eficiência previamente identificadas. Um sistema altamente descentralizado, sem medidas para deixar claras as prioridades e reforçar a ação coordenada em que existem externalidades, pode criar muitos problemas, pois os funcionários tentarão perseguir seus próprios interesses e impor custos aos outros, sem considerar quais sejam esses custos. 
Quadro 3: Documento da reunião do Comitê PUMA, realizada em outubro de 1998

Accountability e transparência: ou seja, quão claras e diretas são as linhas de responsabilidade na determinação e coordenação da estratégia e execução das decisões, e qual é a qualidade da informação disponível para monitorar e avaliar a accountability, segundo:

- a clareza dos poderes decisórios atribuídos aos diferentes atores;

- a clareza das expectativas de desempenho; e

- a clareza dos resultados de desempenho.

Uma seção anterior afirmava que pode haver ganhos consideráveis a partir da descentralização da tomada de decisão - a transferência do poder discricionário para níveis mais baixos. No entanto, como forma de manter sob controle o exercício discricionário, os responsáveis pela tomada de decisão precisam prestar contas de suas ações. Como apontou o Banco Mundial, os incentivos ao comportamento corrupto surgem sempre que os servidores públicos possuem grande poder discricionário e pouca accountability. ${ }^{16}$ Accountability é o quid pro quo essencial para a autonomia gerencial, e ambas são necessárias para se chegar à eficiência. De certa forma, accountability significa exercer pressão pelo desempenho, mas refere-se, fundamentalmente, ao uso legal, democrático e apropriado dos recursos públicos. Accountability é uma condição necessária, mas não suficiente, para enfrentar a corrupção.

Accountability aplica-se em diversas formas e em diversos níveis. Alguns aspectos da accountability podem ser pessoais e fazer parte do sistema de gestão e controle. Outros aspectos dizem respeito à accountability sistêmica e, por natureza, referem-se à accountability pública.

Recentemente, de maneira consistente com a crescente transferência de autoridade para níveis mais baixos, houve uma mudança geral na forma de o setor público tentar atingir suas metas. Como vários sistemas de gestão de desempenho no setor privado, o setor público utilizou sistemas de objetivos em cascata, em que cada parte da hierarquia tem clareza sobre o que se espera dela em cada nível ao qual ela responde. Isso tem sido particularmente útil em relacionamentos em que o financiamento é dado em troca da produção de determinados bens e serviços. Essa forma de contratualização de desempenho tem sido utilizada tanto no interior de algumas jurisdições, como também entre as mesmas. ${ }^{17}$

Porém, a accountability pelo valor obtido por investimento público não é, em geral, definida nos contratos que lidam com câmbio e fazem estimativas dos custos de produção. Essa necessidade é mais bem atendida pelas declarações gerais de propósitos de caráter financeiro. De fato, 
padrões gerais para o registro de propósitos financeiros foram desenvolvidos no setor privado, para fornecer aos investidores e financiadores a informação que os auxilie a avaliar o potencial de crédito, e as perspectivas das empresas e, eventualmente, o desempenho dos encarregados de gerenciá-las. De certa forma, os contribuintes e aqueles que fornecem capital aos soberanos têm interesses similares, embora os contribuintes tenham grande dificuldade de gerenciar sua exposição ao risco. ${ }^{18}$

Atualmente, existem vários modos diferentes pelos quais os governos relatam sua posição financeira aos parlamentos e cidadãos. Nos últimos anos, houve uma migração para o uso de contabilidade em tempo real (accrual based accounts). Oito países da OCDE comprometeram-se a fornecer completas declarações de acréscimo (accrual statements) do governo, três dos quais são membros do G-7.

Embora muitos dos instrumentos de accountability tendam a abordar as transações que envolvem recursos financeiros, eventos e desempenho por meio de contratos, pode-se exercer pressão constante por uma tomada de decisão de qualidade, por meio da existência de processos transparentes e facilmente compreensíveis.

É possível que nem sempre haja ganhos diretos para os cidadãos, de modo que para eles valha a pena investir tempo e esforço para entender e formar opinião a respeito da maioria das informações prestadas pelo governo. Isso sugere que os cidadãos podem se restringir a informações limitadas antes de tomar uma decisão, mas eles delegam a aquisição geral da informação, e as funções de análise e avaliação para outros. ${ }^{19}$ Essa "ignorância racional" pode conspirar com incentivos para que as agências governamentais e os formuladores de políticas públicas evitem que a informação necessária a respeito do governo flua para o domínio público.

Podem existir vários incentivos que convençam os servidores públicos mais graduados em favor da confidencialidade. Em primeiro lugar, os ganhos com a transparência são, muitas vezes, distribuídos por todos, e não capturados individualmente, o que sugere que há um subinvestimento sistemático no esforço pela transparência. A qualquer momento, a avaliação que um gerente faça do próprio custo-benefício pode indicar que seu tempo pode ser mais bem aplicado em qualquer outra atividade que não seja o cumprimento das exigências da transparência. Em segundo lugar, o controle da informação pode contribuir para o controle da agenda. Isso pode provocar a utilização da disseminação da informação de forma oportunista. Em terceiro lugar, a abertura pode fornecer informação a respeito de erros e fracassos nos julgamentos. Essa é uma razão clássica para escondê-la. Em quarto, o comportamento corrupto tem suas bases na confidencialidade.

A confidencialidade pode contribuir para minar a participação no processo democrático. Os cidadãos confiam principalmente nos mecanismos de "voz" para influenciar as políticas públicas. Porém, a voz, na ausência de informação de qualidade, torna-se pouco mais do 
que barulho. A tendência de os cidadãos se tornarem ignorantes racionais sugere que os custos para que o público adquira, analise e avalie a informação que fornecerá a voz mais viável no processo democrático precisam ser reduzidos. Uma maneira de fazê-lo é o governo comprometer-se com a credibilidade, com a abertura e a transparência. As instituições da informação pública, como os meios de comunicação, a oposição, os institutos de pesquisa, as agências de classificação de risco etc., podem assim reduzir os custos para os cidadãos, ao realizarem grande parte do processamento da informação. Isso cria uma dinâmica positiva de pressão sobre o desempenho do governo, porque, mesmo que nem todas as peças de informação tenham sido influenciadas, sempre existirá a chance de que elas o sejam.

O compromisso com a livre informação e a suposição de que haverá abertura podem reduzir os custos governamentais de longo prazo. Como afirma Stiglitz, "atualmente, todos reconhecem que a informação de qualidade e no momento certo resulta em alocações de recursos melhores e mais eficientes". ${ }^{20}$

Da mesma forma, a informação de má qualidade pode inviabilizar os objetivos de eficiência do sistema de gestão e controle, o que resultará na má alocação sistemática de recursos, por causa da falta de neutralidade (econômica) competitiva entre os fornecedores do setor governamental e aqueles do setor privado. A tendência de oferecer bens e serviços vindos de fornecedores governamentais pode reduzir a inovação e levar a custos maiores no decorrer do tempo.

\section{O papel do Poder Legislativo}

\section{Quadro 4: Documento da reunião do Comitê PUMA, realizada em outubro de 1998}

Papel do Poder Legislativo: qual é o papel do Poder Legislativo na estratégia, na coordenação, na gestão, no controle e na accountability, ou seja:

- Como são definidos os direitos entre o Poder Executivo e o Poder Legislativo?

- Como são gerenciadas as relações entre o Poder Executivo e o Poder Legislativo?

Pode-se esperar que o papel do Poder Legislativo nos processos de orçamento e gestão varie intensamente de acordo com as influências constitucionais e históricas, entre outras. Em geral, no entanto, o Legislativo tem desempenhado um papel mais ativo no processo orçamentário em vários países-membros, ao passo que em outros se percebem mudanças na sua forma de relacionamento.

Em muitos países-membros, as mudanças mais comuns no papel do Legislativo não aumentaram diretamente seu poder com relação ao Executivo. Ao contrário, elas foram desenhadas para melhorar a qualidade 
da discussão do orçamento pelo Legislativo. A esse respeito, podem observar quatro áreas específicas:

- a introdução de declarações de política fiscal, em que o Poder Legislativo discute níveis agregados da arrecadação, gasto, déficit e dívida governamentais, vários meses antes da introdução propriamente dita do orçamento. Tais atos são uma forma de "trancar" duplamente os agregados fiscais, ajudando a gerenciar o problema da "tragédia dos comuns" e controlar as demandas tanto do Executivo quanto do Legislativo;

- um aumento no papel dos comitês legislativos para a discussão do orçamento e uma divisão pronunciada da responsabilidade entre comitês de orçamento e comitês setoriais, em que os comitês setoriais têm a responsabilidade primordial pela alocação final das apropriações dentro do total geral determinado para seus setores. Isso aceita o fato de que a fonte de informação e preferências do Legislativo tenha lugar e voz em uma consideração aberta das medidas orçamentárias, desde que a consideração enfrente uma forte redução no orçamento;

- uma melhoria na preparação de relatórios para o Legislativo, especialmente em termos de melhores informações sobre produtos e resultados, em lugar da informação sobre insumo fornecida tradicionalmente. Isso implica a aceitação da lógica dos sistemas de gestão descentralizados; em contrapartida, ao passar adiante alguns dos seus poderes decisórios o Poder Legislativo passa a demandar novas formas de informação; e

- mais recursos para o Legislativo no momento da discussão do orçamento, seja pelo aumento de recursos dos comitês relevantes, pelo estabelecimento de secretarias legislativas independentes que fornecem aconselhamento especializado sobre orçamento ou pela oferta de mais recursos para os partidos políticos, possibilitando que eles tragam conhecimento especializado no momento da discussão orçamentária. Isso implica que, uma vez tomada a decisão de engajar membros do Executivo no processo, o valor dos recursos aumenta de acordo com a qualidade de tal engajamento, o qual, ao menos em parte, dependerá dos recursos disponíveis para alimentá-lo.

$\mathrm{Na}$ busca de seus objetivos, o Legislativo deverá engajar suas próprias agências, ou, de outra forma, tornar-se-á totalmente dependente das solicitações feitas pelo Executivo. Ao engajar suas próprias agências, o Legislativo deve ser claro a respeito dos aspectos de desempenho sobre os quais ele busca julgamento. De forma geral, o Legislativo não tem o perfil ideal para ser um proprietário eficiente de organizações de médio porte. E caso, por qualquer razão, ele tenha se tornado um proprietário de qualquer organização, ele se encarregará de desempenhar um papel de proprietário e garantir que seus direitos de proprietário sejam reafirmados com relação à gestão de desempenho. 


\section{A transformação gerencial}

Quadro 5: Documento da reunião do Comitê PUMA, realizada em outubro de 1998

- Transformação gerencial: quais sistemas criam processos dinâmicos para "desafio e mudança", incluindo a capacidade de antecipar e encarar os choques ou outras necessidades inesperadas de mudança na estratégia, na estrutura ou na capacidade de executar as prioridades governamentais. Como se reúne a informação de modo a alimentar tal atividade estratégica de análise?

O pressuposto inicial desta estrutura de análise é que muitas abordagens tradicionais da gestão pública não tratam de forma satisfatória os três objetivos de eficiência almejados. A mudança de sistemas "lineares" de comando e controle para modelos de devolução de "direção" "tem sido uma megatendência entre os sistemas governamentais de orçamento e gestão, durante a última década. Isso não significa que todos os governos embarcaram nessa jornada com o mesmo grau de fervor, mas é razoável afirmar que todos os países-membros — com pontos de partida variados e velocidades distintas - abraçaram alguns aspectos da reforma.

A estratégia de reforma apropriada dependerá de várias condições locais, mas há aspectos da mudança gerencial que, espera-se, contribuirão para as transições mais bem-sucedidas. Pode-se esperar que a maior parte das seguintes características estejam presentes em tais mudanças gerenciais:

- forte patrocínio ou condução por parte dos líderes políticos;

- evidência de bipartidarismo, que tem o efeito de aumentar a credibilidade do programa de reforma e tirar as mudanças do papel;

- capacidade institucional de gerenciar a implementação;

- coerência na ação, o que significa, por exemplo, que os tipos de mudança que se aplicariam a uma área seriam informados pelas reformas realizadas em outras áreas, de modo a serem reforçados;

- amplitude, de modo que a abordagem da reforma seja aplicada em todo o setor público e em todos os aspectos relevantes da gestão pública; e

- incentivos para que os atores do sistema alinhem-se às metas sistêmicas e não a outras metas.

Reconhece-se que, em muitas administrações, é difícil implementar estruturas abrangentes e logicamente consistentes por todo o governo. Não obstante, espera-se que os primeiros quatro pontos sejam bons indicadores de um provável poder duradouro da transição. Porém, uma vez implementados — mesmo sob o impacto de uma mudança inicial abrangente - os sistemas precisam adaptar-se para se ajustarem a circunstâncias e 
comportamentos mutáveis. Muitas dessas adaptações acontecerão como uma resposta oportuna, assim que os eventos o permitam. A consideração de quanto os governos aprendem e como convertem o aprendizado relevante em mudança pode se apresentar como um indicador de capacidade dinâmica. Alguns requisitos centrais propostos por uma autoridade nacional $^{21}$ incluem:

- abertura à experimentação e inovação (sem laços com o passado); - compromisso com auto-escrutínio honesto;

- disposição de se engajar com outras instituições e de lidar com a crítica e a tensão; e

- formas sistemáticas de testar e comunicar novas idéias.

\section{Notas}

* Texto traduzido sob a responsabilidade da ENAP Escola Nacional de Administração Pública da edição original em inglês, sob o título: Budgeting and Management Country Studies - Proposed Framework (PUMA/SOB(99)7). Copyright OECD, 1999. A OCDE não se responsabiliza pela qualidade da tradução em português e sua coerência com o texto original. 20ª Reunião Anual dos Diretores de Orçamento, Paris, 3 e 4 de junho de 1999.

${ }^{1}$ Simpósio "Government for the Future... Getting from here to there" — a ser lançado (OCDE).

${ }^{2}$ CAmpos, J., Pradhan, S. (1997), "Evaluating public expenditure management systems: an experimental methodology with an application to the Australia and New Zealand reforms". Journal of Policy Analysis and Management, Edição de Verão, p. 423-445.

${ }^{3}$ Ver Schick (1998), The Changing Role of the Central Budget Office, OCDE/PUMA, p.3; e em A Contemporary Approach to Public Expenditure Management, The World Bank Group EDI, p.2.

${ }^{4}$ Schick, por exemplo, fala de uma divisão em três aspectos — entre regras, papéis e informação - como sendo o modelo-chave para identificar e codificar a abordagem da alocação de recursos em apoio aos objetivos de eficiência (Schick, p. 16-27).

${ }^{5}$ Pollitt, C., Ocde. (1999), Performance Management and Financial Managment: How to integrate them?. PUMA/SBO (99)4.

${ }^{6}$ Nota do Revisor: Delegação aqui está no sentido de prerrogativo na definição do orçamento que será devolvido às unidades.

${ }^{7}$ Ver, por exemplo, Wilson, J. (1989), Bureaucracy. EUA: Basic Books.

${ }^{8}$ PollitT, Loc Cit.

${ }^{9}$ Ocde-Puma. (1997), In Search of Results.

${ }^{10}$ Nota do Tradutor: $\mathrm{O}$ autor refere-se à hierarquia de objetivos, dentro do marco lógico.

${ }^{11}$ Muitos escritores investigaram o fenômeno de "aversão à perda", que sugere que as preferências podem ser manipuladas por mudanças no ponto de referência. Isso indica que regras deveriam ser criadas para baixar as linhas de base, permitindo-se que os Ministérios as elevassem, tendo assim uma percepção de "ganho". Ver, por exemplo, Kahneman, D., Tversky, A. "Prospect Theory: An analysis of decision under riks". Econometrica, vol. 47, no 2, p. 263-291. 
${ }^{12}$ Schick, A. (1976), The Spirit of Reform. Nova Zelândia: Comissão de Serviços Estatais, p.54.

${ }^{13}$ Um caso é o uso de servidores públicos com cargos elevados, empregados em nível central, ao invés de permitir que esses servidores sejam contratados por agências. Isso permite que a gerência desses servidores, como um corpo funcional, forneça uma estrutura de carreira, reduza os custos de transação associados à sua mobilidade e forneça coesão corporativa por todo o governo. Ver Ocde/Puma., Ingraham, P. M., Murlis, H., Peters, G. (1999), The state of the higher services after reform. PUMA/HRM (99)1.

${ }^{14}$ Ver, por exemplo, KaPLAN, R. (1982), Advanced Managment Accounting, Prentice-Hall. EUA, p. 431-450.

${ }^{15}$ Stiglitz, J. (1999), Participation and development perspectives from the comprehensive development paradigm. Observações feitas à Conferência Internacional sobre Democracia, Economia de Mercado e Desenvolvimento, p.8.

${ }^{16}$ Banco Mundial. (1997), The State in a changing world. EUA: World Bank Group, p.13.

${ }^{17}$ Ocde-Puma. (1999), Accountability Management and Intergovernmental Partnership. PUMA/RD(99)4; e Public Sector Performance Contracting. PUMA/RD(99)5.

${ }^{18}$ Esta é uma questão levantada por STIGLITZ, David. How should governments invest financial assets and manage debt, PUMA/SBO/RD (99)1.

${ }^{19}$ Este argumento é levantado em vários lugares. Ver, por exemplo, ChAn, J. L., Rubing, M.A. "The role of information in a democracy and in government operations: the public choice methodology". Research in Government and Non-profit Accounting, vol. 3 (parte B), p. 10-12.

${ }^{20}$ STIGLITZ. (1999), On liberty, the right to know, and public discourse: the role of transparency in public life. Oxford Amnesty Lecture, p.9.

${ }^{21}$ Comissão de Serviços Estatais. (1998), "Assessment of the State of the New Zealand Public Service”. Occasional paper, no 1, outubro, p. 25-26.

\section{Referências bibliográficas}

Asian Development Bank. (1999), Managing Govenrment Expenditure.

Banco Mundial. (1998), Public Expenditure Handbook. EUA: World Bank Group.

BARKER, G. (1996), “A comparative institutional approach to law and legal institutions”. In Essays in Law and Economics. Victorian University of Wellington Law Review, vol. 26, no 1 , p. 109-141.

Bernstein, P. (1998), Against the Gods. EUA: John Wiley.

BLondAL, J. (1998), "Financial Management for National Governments”. Discurso proferido no 11ํㅡㄹ Colóquio Anual de Gestão Financeira para Governos Nacionais. Montreal, Canadá, 20-23 de setembro.

Boston, J. et al. (1996), Public management. Australia: Oxford.

Brumby, J., Edmonds, P., Honeyfield, K. (1996), The effects of financial management reform in the New Zealand public sector. Documento para a Australasian Evaluation Society, Wellington.

BUITER, W. (1996), Principles of budgetary and financial policy. EUA: MIT.

Campos, J., Pradhan, S. (1997), "Evaluating public expenditure management systems: an experimental methodology with an application to the Australia and New Zealand reforms". Journal of Policy Analyis and Management, Edição de Verão, p. 423-445. 
Chan, J. (s.d.), "Accounting and financial management reform in the United States government”, in BuschOR, E., SCHEDLER, K. Perspectives on performance measurement and public sector accounting. Suíça: Institute of Public Finance and Fiscal law.

Congleton, R. (1991), "Rational ignorance, rational expectations and fiscal illusion”. In Papers in Political Economy. Canadá: University of Western Ontario.

Douglas, R. (1996), Unfinished business. Nova Zelândia: Random.

HART, O. (1996), Firms, contracts and financial structure. UK: Claredon Press.

Hood, C. (1991), “A public management for all seasons”. Public Administration, vol. 69, Edição da Primavera.

Hussey, D. (1998), Strategic Management. Reino Unido: Butterworth.

International Federation Of Accountants (Public Sector Committee). (1998), Guideline for governmental financial reporting. EUA: IFAC.

Kahneman, D., Tversky, A. (s.d.), "Prospect Theory: An analysis of decison under risk". Econometrica, vol. 47, nำ2, p. 263-291.

KaPlan, R. (1982), Advanced Management Accounting. EUA: Prentice-Hall.

KotTER, J. (1996), Leading change. EUA: HBS.

LÖFFLER, E. (1997), The modernisation of the public sector in an international comparative perspective. Alemanha: Speyer.

McMillan, J. (1992), Games, Strategies and Markets. Reino Unido: Oxford University Press.

Milgrom, P., Roberts, J. (1992), Economics, Organization \& Management. EUA: PrenticeHall.

Mueller, D. (1993), Public Choice II. Reino Unido: Cambridge.

Niskanen, W. (1996), Bureaucracy and public economics. EUA: Locke Institute.

OCDE. (1997), In Search of results - Performance management practices.

Ocde-Puma. (1998), Role of the Legislature. PUMA/SBO(98)4.

Ocde-Puma; BALL, I. (1998), Modern Financial Management Practices. PUMA/SBO(98)8/ Final.

Ocde-Puma; Keating, M. (1998), Public management reform and economic and social development. PUMA/SBO(98)9.

Ocde-Puma; Anderson, B. (1999), Budgeting in a Surplus Environment. PUMA/SBO/ $\mathrm{RD}(99) 1$.

Ocde-Puma; Pollitt, C. (1999), Performance Management and Financial Management How to Integrate them?. PUMA/SBO(99)4.

Ocde-Puma; Skilling, D. (1999), Managing Financial Assets. PUMA/SBO/RD(99)1.

Ocde-Puma; STRAuch, R. (1999), Managerial Flexibility and Fiscal Performance. PUMA/ $\mathrm{SBO} / \mathrm{RD}(99) 2$.

Osborne, D., Gaebler, T. (1992), Reiventing government. EUA: Addison-Wesley.

Petrei, H. (1998), Budget and Control. BID.

Putnam, R. (1993), "Diplomacy and domestic policy: the logic of two level games", in

Evans, P., et al., Double-edged diplomacy. EUA: University of California, p. 431-468.

SCHELling, T. (1978), Micromotives and macrobehavior. EUA: Norton.

SCHICK, A. (1998), The changing role of the central budget office. OCDE. . (1996) The spirit of reform. Nova Zelândia: SSC.

. (1998), A contemporary approach to public expenditure management.

EUA: Banco Mundial.

SchleIFER, A., Vischny, R. (1998), The Grabbing Hand. EUA: Harvard.

Scott, G., BALl, I., DAdE, T. (1997), "New Zealand's public sector management reform, Implications for the United States". Journal of Policy Analysis and Management, Edição de Verão, p. 357; 381. 
Stiglitz, J. (1999), On liberty, the right to know and public discourse; the role of transparency in public life. Oxford Amnesty Lecture.

. (1999), "Public policy for a knowledge economy". Palestra proferida no Center for Economic Policy Research, Reino Unido.

Watts, R., Zimmerman, J. (1986), Positive accounting theory. EUA: Prentice-Hall.

Wilson, J. (1989), Bureaucracy. EUA: Basic Books. 


\section{Os problemas da integração apresentados por Pollitt}

A integração da gestão de desempenho com a gestão financeira enfrenta tanto dificuldades técnicas quanto potenciais resistências comportamentais e políticas. Elas incluem os seguintes fatos:

- Os processos orçamentários estão entre as rotinas mais fortemente enraizadas do governo e envolvem atores poderosos e interesses políticos consideráveis, sempre a respeito de temas distributivos cruciais. Portanto, criar ligações estreitas entre a mudança em tais processos e a introdução de esquemas de gestão de desempenho pode, por vezes, complicar o processo, multiplicando o número de obstáculos a serem enfrentados e, geralmente, aumentando o risco de que o processo de reforma fracasse em atingir suas metas. A gestão de desempenho já enfrenta dificuldades suficientes para ser implementada. Tentar, ao mesmo tempo e em um só processo, implementar gestão de desempenho e reforma orçamentária pode aumentar as chances de que ambas fracassem. Como afirma Mayne (1996: 13): "Embora seja necessário um consenso para a implementação da gestão baseada em resultados, as tensões são ainda maiores, quando o objetivo é relacionar desempenho com alocação de recursos". Portanto, isso não é uma barreira insuperável, mas, sim, uma questão de administrar a mudança e garantir que, mesmo que os sistemas se desenvolvam em ritmos diferentes, eles estejam suficientemente coordenados para, no mínimo, não atuarem um contra o outro. Pode-se definir esse problema como "tentar fazer muito ao mesmo tempo".

- Alguns comentaristas argumentam que sempre haverá situações nas quais as exigências do processo político que cercam o orçamento e as exigências dos processos gerenciais que caracterizam a melhoria do desempenho estão em tensão umas com as outras. $\mathrm{O}$ argumento é que, para superar os desafios distributivos complexos e sensíveis contidos no processo orçamentário, os políticos tanto do Executivo quanto do Legislativo, precisam apelar para valores vagos e gerais, para criar ou manter coalizões suficientemente amplas de apoio ou, ao menos, aceitação para a continuidade de um programa e o corte de outro (ver, por exemplo, Le Loup et al., 1998). A última coisa que os interessa, durante esse processo delicado e freqüentemente cheio de adversidades, são avaliações comparativas de programas rivais ou especificações muito precisas de prioridades e metas 
operacionais (ver, por exemplo, Jones e McCaffrey, 1997: 39; Monnier, 1992: 18). Tais exercícios somente serviriam para indicar claramente "quem ganha e quem perde", e qual é o custo-efetividade relativo de diferentes programas, tornando, assim, a coalizão/gestão ainda mais difícil. O progresso da gestão de desempenho, ao contrário, requer que os participantes discutam e acertem objetivos, metas e padrões realistas, mensuráveis e com prazos definidos, com uma identificação altamente específica de grupos de clientes e suas preferências. Embora não seja preciso acreditar que contradições desse tipo devam sempre existir, seria ingênuo fingir que as exigências da barganha orçamentária nunca entram em conflito com os princípios da boa gestão de desempenho. A isso poderíamos chamar de uma questão de "conforto da ambigüidade". Esse ponto levanta uma questão interessante: verificar se os fluxos de procedimento e informação podem ser desenhados de forma a encorajar os políticos encarregados da tomada de decisões a abrirem mão do conforto da ambigüidade para abraçar uma posição mais informada. Essa é uma questão delicada, mas alguns países estão ao menos começando a tentar envolver os políticos nesses assuntos e a preparar sessões de informação para necessidades específicas.

- Os incentivos que mantêm uma certa opacidade ou, ao menos, evitam comparações bem fundamentadas entre programas não afetam somente os políticos. Servidores públicos podem também ser motivados a proteger "seus" programas e, ao fazê-lo, podem não dar as boas-vindas aos esquemas que pregam a completa transparência financeira e de desempenho. O problema da "defesa da sua área", que também pode ocorrer em nível de agências e departamentos, é bem conhecido. Nos EUA, por exemplo, apesar da grande reforma da legislação sobre gestão no início dos anos 90:

"ficam (aqui) mantidos muitos incentivos reais para que departamentos e agências escondam seus gastos totais com bem-estar social, defesa nacional, gestão de terras públicas, transporte, energia e outros programas no processo decisório do orçamento federal. (Jones e McCaffrey, 1997: 49. Ver também Gianakis, 1996: 134).

- Existe também o que se costuma chamar de divergência cultural entre gestão financeira e de desempenho. Dadas as constantes pressões vindas da base sobre o gasto público, a gestão financeira é, ao menos, em parte, um processo de disciplina e controle. Departamentos centrais de finanças e de tesouro lutam para moderar as demandas dos departamentos executores e para lembrar os demais ministros da necessidade de dar prioridade às considerações macroeconômicas, que se encontram fora das metas sociais, estratégicas e gerenciais particulares, que dão informação e motivação à maior parte dos principais programas governamentais: bem-estar social, saúde, educação, defesa etc. Ao contrário, muitas das iniciativas para melhoria do desempenho enfatizam os 
profundos valores sociais de determinadas metas a serem atingidas por programas específicos, a necessidade de trabalho de equipe, parceria e compromisso, para melhoria contínua, e a exigência suprema de sensibilidade para com os clientes. Assim, existe o que pode ser descrito não tanto como uma contradição, mas, sim, como uma diferença de humor entre o orçamento de nível mais alto e os esquemas de melhoria de desempenho. Isso poderia ser definido como o problema das "restrições ou empoderamento". Ele pode se manifestar de várias formas distintas, incluindo tensões entre os departamentos de gestão financeira e de recursos humanos e entre os que defendem uma abordagem "dura", de corte de números, e aqueles que preferem enfocar temas mais leves, como qualidade, mudança cultural e desenvolvimento de capacidades.

- Uma dificuldade técnica séria ocorre quando o sistema de gestão de desempenho inclui medidas de efetividade. Em vários países, governos e especialistas reconheceram a necessidade de avançar de medidas de produto (geralmente medidas de eficiência) para medidas de resultado (eficácia - ver, por exemplo, East, 1997). Um sistema equilibrado de gestão de desempenho precisa das duas. De fato, medidas de resultados podem ser divididas em duas categorias: medidas de eficácia ou medidas de melhoria no planejamento de políticas, em vez de medidas de impacto, isto é, ferramentas para formulação de políticas públicas em lugar de manutenção da accountability (Schick, 1996). A dificuldade surge, no entanto, se houver uma tentativa de relacionar as alocações orçamentárias às medidas de eficácia. Embora isso possa soar como bom senso, de fato envolve diversos problemas. "O obstáculo primordial à integração da mensuração de desempenho e da elaboração do orçamento é que ela requer medidas de produtos difíceis de se construirem, para programas do setor público" (Gianakis, 1996: 140. Para uma expressão mais detalhada, mas essencialmente igual, ver Wildavsky, 1979: 32).

As razões para tanto são várias. Para começar, a muitos programas, as mudanças nos resultados se dão em intervalos de tempo muito maiores do que o ano orçamentário. Assim, as mudanças nos resultados deste ano provavelmente não refletirão, de forma alguma, os esforços dos atuais gerentes governamentais. Além disso, muito freqüentemente, os resultados são somente, em parte, determinados pelos programas governamentais - existem muitas outras variáveis determinantes além do controle dos gerentes - e relacionar recursos a resultados é, portanto, injusto, em maior ou menor grau (Pollitt, 1997). Aqui existe, portanto, uma questão de "atribuição de resultados". Por último, é preciso reconhecer que, politicamente, para muitos programas, o fracasso em atingir resultados não significa que os recursos deveriam ser retirados e os programas abandonados. Os objetivos políticos originais - redução da pobreza, da criminalidade, criação de empregos - continuarão importantes como nunca. Pode mesmo ser o caso de se alocarem mais recursos para a 
tarefa, modificando-se, ao mesmo tempo, os programas, na esperança de se chegar a maior efetividade. Em suma, ligações automáticas, com fórmulas mágicas, entre medidas de eficácia e alocações orçamentárias serão raramente aceitáveis, tanto do ponto de vista técnico quanto político. Isso não significa uma barreira à integração, mas, sim, um reconhecimento de que, onde a integração entre a informação relativa ao desempenho e a informação financeira não puder ser alcançada, não se deve pressupor como conseqüência o baixo desempenho, para que haja cortes no financiamento. Por exemplo, pode ser que aqueles que tinham autoridade para tomar decisões tenham tido sua autoridade revogada.

Reconhecer que existem barreiras ou dificuldades com a integração é uma coisa; concluir que a integração é impossível é outra completamente diferente, e, com as evidências disponíveis, esta seria uma conclusão precipitada e sem garantias. Para levarmos a discussão adiante, é necessário que sejamos mais específicos a respeito dos tipos particulares de integração que desejamos e dos contextos particulares nos quais tais esforços deverão ter lugar.

\section{Quadro 6: Variáveis-chave para a integração}

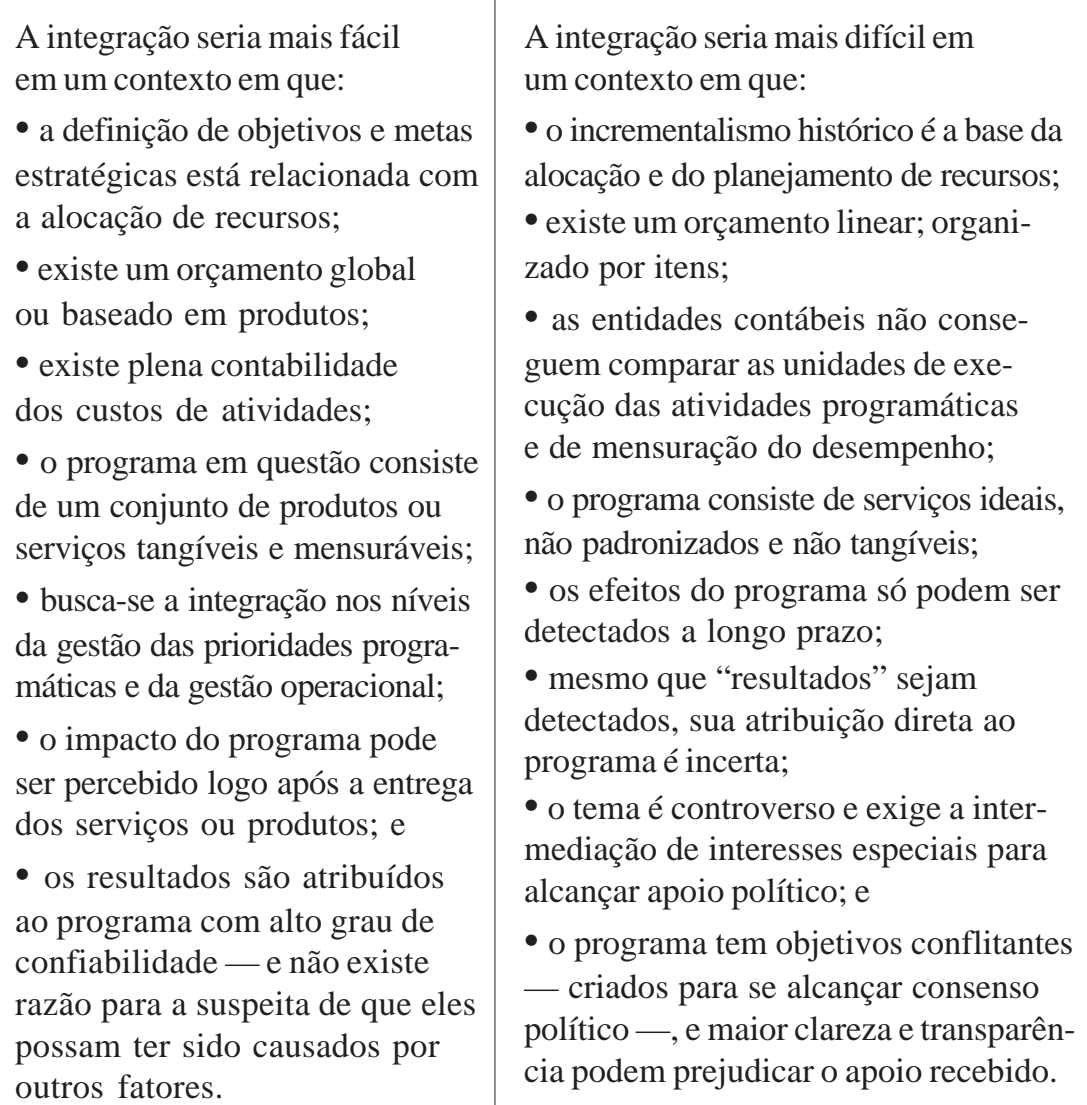


Revista do

Serviço

Público

Ano 53

Número 4

Out-Dez 2002

Organização

para a

Cooperação e o Desenvolvimento

Econômico (OCDE), Paris

França.

Contato:

www.oecd.org

\section{Estudos sobre orçamento e gestão nos países da OCDE — uma proposta de estrutura}

Serviço de Gestão Pública/Comitê de Gestão Pública - PUMA/OCDE

O Comitê de Gestão Pública da OCDE (PUMA) definiu como um dos principais produtos de suas atividades a realização de análises de sistemas nacionais de orçamentação e gestão de seus países-membros. O presente documento detalha a estrutura proposta para a realização dessas análises baseadas em seis questões principais: estratégias, coordenação, gestão e controle, accountability e transparência, o papel do Poder Legislativo e transformação gerencial.

\section{Estudios al respecto de presupuesto y gestión en los países de OCDE — una propuesta de estructura \\ Serviço de Gestão Pública/Comitê de Gestão Pública - PUMA/OCDE}

El Comité de Gestión Pública de $O C D E$ (PUMA) definió como uno de los principales productos de sus actividades la realización de análisis de sistemas nacionales de presupuesto y gestión de sus países miembros. El presente documento detalla la estructura propuesta para la realización de esos análisis basados en seis cuestiones principales: estrategias, coordinación, gestión y control, accountability y transparencia, el papel del poder legislativo y transformación gerencial.

\section{Studies on budgeting and management in OECD member countries - a structural proposal}

Serviço de Gestão Pública/Comitê de Gestão Pública - PUMA/OCDE

OECD's Public Management Committee (PUMA) defined the performance of an analysis of national budgeting and management systems of its member countries as one of the main products of its activities. This document details the structure proposed to the performance of these analyses, based in six main questions: strategies, coordination, management and control, accountability, transparency, the role of the legislative power and the managerial transformation. 